\title{
Audiencias, ciudadanos y prosumidores en los medios digitales: el caso de Alexei Navalny y la Snow Revolution
}

Daniel Higuita Olaya*

DOI: https://doi.org/10.17230/9789587206289ch11

\section{Introducción}

"Es difícil decir cuántas personas hubo hoy en la Plaza Bolotnaya de Moscú"; con esta frase, Julia Loffe comienza su reporte sobre la protesta realizada allí el 10 de diciembre de 2011. Esta sería la primera de varias manifestaciones de protesta que se extenderían hasta 2013 en el territorio ruso. Designado por la prensa internacional como Snow revolution, este movimiento tuvo una característica muy particular: la multitud, que asombraba a Loffe en su reporte, fue convocada en su gran mayoría por medio del uso de las redes sociales en la web. Adicionalmente, el movimiento de oposición al gobierno de Vladimir Putin se caracterizó por un alto nivel de uso y apropiación de las Tecnologías de la información y la comunicación (TIC) en sus estrategias de denuncia, convocatoria y acción.

Imagen 1. Plaza Bolotnaya desde el puente Luzhkov de Moscú, 10 de diciembre de 2011

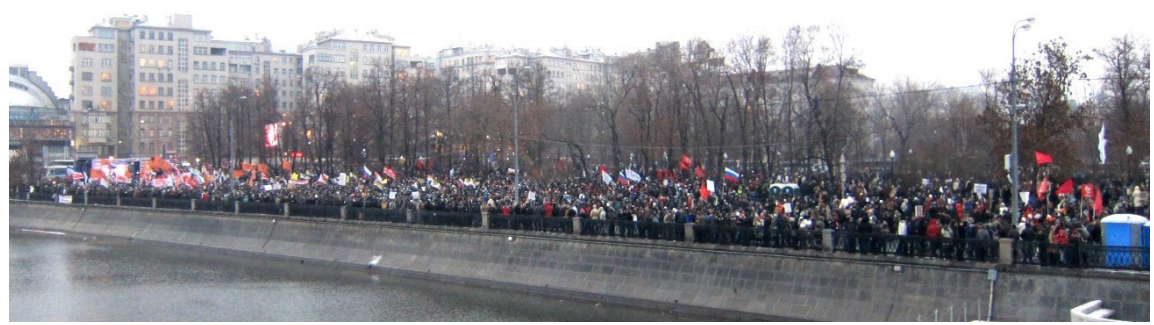

Fotografía de Bogomolov.PL. Obtenido de Wikimedia Commons (http://bit.ly/2nlI0la).

* Comunicador Audiovisual del Politécnico Colombiano Jaime Isaza Cadavid, magíster en Comunicación Transmedia de la Universidad EAFIT, Medellín. Profesor en los núcleos de Transmedia e Hipermedia en el Politécnico Colombiano Jaime Isaza Cadavid. Correo electrónico: dhiguit5@eafit.edu.co 
Por ello es pertinente analizar el comportamiento de las personas en situaciones en las que su posibilidad de expresarse tiene limitaciones, pero los individuos conservan aún su capacidad de estar conectados online y esto les permite, de una u otra manera, ejercer su ciudadanía. En relación con estos actores, Pilgun y Gradoselskaya sostienen que, en el caso ruso, los comportamientos de estos ciudadanos que se comunican políticamente se caracteriza por:

[...] su alta actividad en la red porque participan en un amplio número de grupos y dejan una gran cantidad de comentarios. Actores de este tipo están muy bien preparados para la interacción comunicativa digital, usan y dominan a la perfección diferentes registros de medios lingüísticos, comunicativos e integrados (medios de comunicación de canales variables, televisión, internet, plataformas, etc.) [...] Saben evaluar con precisión una situación comunicativa concreta y elegir medios adecuados para influir en el destinatario (Pilgun y Gradoselskaya, 2015, p. 734). ${ }^{1}$

Este sujeto consciente, capacitado y activo, está en condición de generar nuevos instrumentos que posibiliten el ejercicio de la ciudadanía de otros:

En el contexto de una crisis especialmente grave de la representación política en la Rusia contemporánea, los ciudadanos -los programadores individuales o movimientos sociales- desarrollan estas nuevas herramientas utilizando las posibilidades técnicas de las TIC y las comunicaciones móviles con el fin de posibilitar la vigilancia, el juicio y el control de las administraciones locales (Ermoshina, 2014, p. 25).

Contrario a lo que se pensaba sobre la audiencia en el siglo XX, entendida como una masa o como un destinatario a persuadir, codificando, decodificando, mirando, leyendo o escuchando, pero sin participar nunca activamente del proceso comunicacional, hoy en día el concepto gira en torno a las ideas de una ciudadanía vigilante, activa y consciente. Este ciudadano es capaz no solo de procesar los mensajes, sino de ir en busca de ellos, intervenirlos o producirlos; es por ello que se habla ahora de un usuario empoderado que realimenta el proceso comunicacional al ser, además de audiencia, productor de contenido o prosumidor. ${ }^{2}$

1 Las traducciones de las citas son de mi autoría.

2 Concepto descrito por Alvin Toffler en La tercera ola (1981), cuya definición más simple es la de una persona que consume contenidos a la vez que los produce. Se hace pertinente en el momento de analizar las formas de interacción de las audiencias contemporáneas y las dinámicas con las que se construye la idea de transmedialidad. 
Ahora bien, Maria Pilgun y Galina Gradoselskaya (2015) y Ksenia Ermoshina (2014) centran sus estudios en el uso y apropiación de las TIC como herramientas de ciudadanía y comunicación política; las primeras hacen un análisis del comportamiento en Facebook del usuario ruso y la segunda se focaliza en el desarrollo de aplicaciones web para el empoderamiento de las ciudadanías en Rusia. Sin embargo, a la luz del interés de este texto es necesario hacer una reflexión sobre cómo se apropian los ciudadanos de las TIC para comunicarse y cómo estas apropiaciones pueden componer un relato comunicacional transmedia (Jenkins, 2003; Kinder, 1991).

En relación con lo anterior, este trabajo tiene como objetivo hacer un análisis de las acciones realizadas por la oposición al gobierno de Vladimir Putin que fueron mediadas por las TIC y que, por su naturaleza, podrían configurar una estrategia de comunicación transmedia para la movilización social. Siendo los blogueros de la oposición ampliamente reseñados por haber sido actores clave en el movimiento y por basar su activismo en la internet y demás medios digitales (Osborn, 2011; Shuster, 2012; Weir, 2011), se hace hincapié en la serie de contenidos realizados y movilizados por Alexei Navalny, líder de la oposición al gobierno de Vladimir Putin y opinador altamente activo en el ciberespacio.

Este trabajo parte de la premisa de que el conjunto de los contenidos producidos por Navalny conforma una estrategia de comunicación transmedia que promueve el prosumo, la visibilidad y la ciudadanía digital. Para el análisis se tienen en cuenta los sitios web relacionados con su fundación Fondo para la lucha contra la corrupción ${ }^{3}$ (creada en 2011 en respuesta a la situación de corrupción en su país), sus redes sociales y las reseñas que fueron escritas por agentes externos al equipo de trabajo del líder político.

En el análisis se destacan las formas de participación del ciudadano como mecanismos para la transmedialización, partiendo de la idea de que una estrategia transmedia está compuesta por tres elementos básicos: diversas formas de relación textual, múltiples plataformas y apropiación por parte del usuario de la producción de contenido (Jenkins, 2008).

3 www.fbk.info 


\section{¿Una revolución? La manifestación como muestra del des- contento}

El proceso de reestructuración económica que se dio en la década de 1990 en Rusia, conocido como la Perestroika (Brics, 2103; Espada, 2016), no solo implicó el fin de la Unión Soviética sino el comienzo de una línea de gobiernos que iniciaron con el de Boris Yeltsin, quien renunciaría el $1^{\circ}$ de enero de 2000, dejando el Kremlin a cargo de su primer ministro Vladimir Putin, quien ha estado en el poder desde entonces, como presidente o como primer ministro del país.

Según Denis Volkov (2012), algunos factores como la recesión económica, el estado de corrupción y la tensión acumulada entre el gobierno y algunos sectores de la esfera política rusa ocasionaron el descontento de una parte de la población hacia el Kremlin. Lo que trajo como resultado una multitud de aproximadamente 50000 personas que salió a protestar el 10 de diciembre de 2011 en contra del gobierno de Putin, cuyo partido político había ganado las recientes elecciones al Parlamento:

El 4 de diciembre de 2001, se llevaron a cabo las elecciones para el cuerpo legislativo, y Rusia Unida obtuvo 52,88\% de las curules. Esa noche, se difundieron rápidamente varios informes sobre distintos tipos de fraude electoral. Los empleados del Estado declararon que fueron presionados por sus superiores para votar por Rusia Unida, los testigos electorales alegaron que los funcionarios electorales rellenaron las urnas y contaron mal los votos a propósito (Global Nonviolent Action Database, s. f).

Las denuncias sobre la corrupción y el fraude fueron ampliamente documentadas y publicadas de inmediato en la web por activistas, periodistas y ciudadanos comunes que en poco tiempo viralizaron estos contenidos en redes como YouTube, Vkontakte, ${ }^{4}$ Twitter y Facebook (Vanden Heuvel, 2015). Rápidamente se convocó por redes una protesta para el 10 del mismo mes en la plaza de Bolotnaya en Moscú con el propósito de exigir la anulación del resultado de las elecciones, la renuncia de Vladimir Churov (líder de la Comisión electoral) y la libertad de los presos políticos (Gabowitsch, 2012; Gessen, 2014; Loffe, 2011).

4 Red social equivalente a Facebook en Rusia; por la cantidad de usuarios es una de las más populares en Europa. A pesar de sus comienzos como una red exclusiva para estudiantes rusos, actualmente puede ser utilizada por todo el mundo; tiene versión en español (www.vk.com). 


\section{Imagen 2. Plaza Bolotnaya de Moscú, 10 de diciembre de 2011}

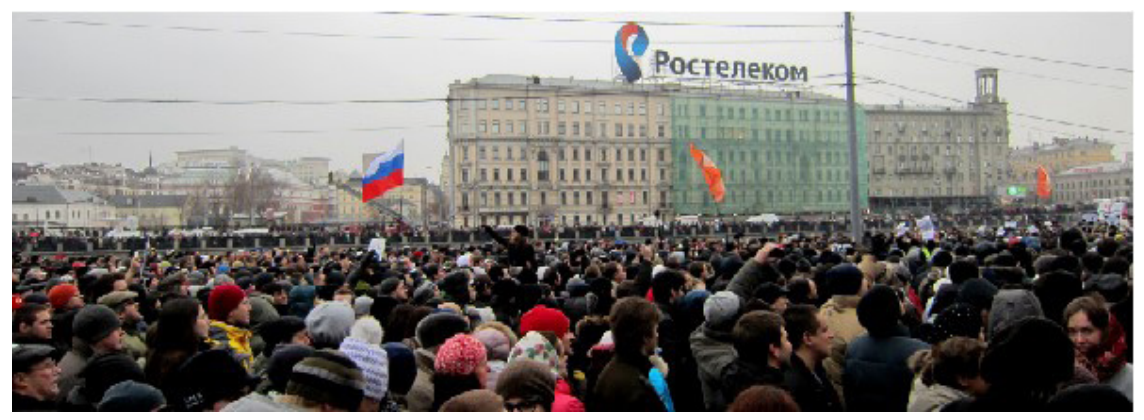

Fotografía de Bogomolov.PL. Obtenido de Wikimedia Commons (http://bit.ly/2omaWZB).

Esta serie de manifestaciones, nombradas por la prensa internacional como Snow revolution, duraron alrededor de dos años ${ }^{5}$ y se extendieron a lo largo del país, caracterizándose por la diversidad en las acciones que se dieron durante dicho período de tiempo y por los mecanismos de convocatoria y participación basados en internet y las redes sociales virtuales.

Dadas las condiciones de censura y las dificultades para las movilizaciones en espacios públicos, los opositores se vieron en la necesidad de evidenciar su descontento valiéndose de diferentes posibilidades para expresarse. Así, se encuentran múltiples estrategias como el uso de blogs y mecanismos alternativos para ocupar los espacios públicos.

La transmedialidad y las estrategias de movilización

En plena transición del nuevo siglo, Henry Jenkins, a propósito de las dinámicas de narración derivadas de la convergencia de medios y de industrias del entretenimiento, escribía que asistimos a nuevas formas de contar que se basan en la multiplataforma como estrategia para abordar al público contemporáneo. Denominó a estos nuevos contenidos narrativas transmedia, caracterizadas por hacer presencia de múltiples maneras, es

\footnotetext{
5 Algunas bases de datos como la Global Nonviolent Action Database (http://bit.ly/2cyKYB6) reseñan la Snow revolution con fechas diferentes, 2011 a 2012 en este caso. Sin embargo, hay un consenso en la mayoría de referencias, incluso las periodísticas y las de enciclopedias comunitarias como Wikipedia, las cuales datan las protestas de 2011 a 2013. En este trabajo se analizan elementos dentro del último rango mencionado, considerando que es importante anotar que hay acciones, tanto previas como posteriores, que pueden ser entendidas como parte del movimiento.
} 
decir, "que una historia puede ser introducida en una película, expandirse a través de la televisión, las novelas y los cómics, y su mundo puede ser explorado y experimentado por medio del juego" (Jenkins, 2003; sin énfasis en el original). La transmedia, concepto acuñado inicialmente por Marsha Kinder (1991), implica repensar las dinámicas de producción de contenidos audiovisuales no solo en términos de ficción, sino también en la producción de relatos como los que pueden tejerse en otros procesos sociales.

Es así como se encuentra una amplia lista de referentes que reflexionan respecto a estrategias de transmedialización de contenidos (Cliff, 2017; Hayes, 2011; Klastrup \& Tosca, 2004; Scolari, 2013). Reflexiones de las que se puede concluir que, en definitiva, se habla de sistemas de relaciones textuales entre medios o "Sistemas intertextuales transmedia" (Montoya, Vásquez y Salinas, 2013).

Retomando el caso, el sistema de contenidos realizados en torno a Navalny se puede agrupar en tres grandes categorías: las redes sociales virtuales, los sitios web y las herramientas web. Respecto a las redes sociales, cuenta con un perfil en cada una de las más populares: Facebook, ${ }^{6}$ Instagram, ${ }^{7}$ Twitter $^{8}$ y Vkontakte, ${ }^{9}$ en las cuales publica actualizaciones de las actividades realizadas tanto por él, como por su fundación o por el movimiento de oposición. Las redes sociales de Navalny hacen constante referencia a sus publicaciones de blog y son actualizadas permanentemente.

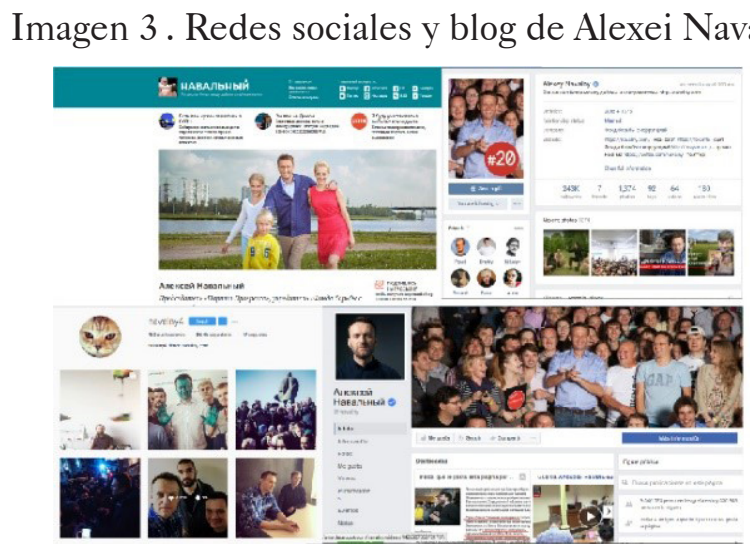

Fuente: Perfiles en Facebook, VKontakte e Instagram y Blogs.

\footnotetext{
www.facebook.com/navalny www.instagram.com/navalny4 www.twitter.com/navalny www.vk.com/navalny
} 
Los sitios web son tres: el blog oficial de Alexei Navalny (www. navalny.com), que reúne las principales publicaciones, escrito en forma de bitácora en la que recoge casos de corrupción en el gobierno y algunas peticiones de ciudadanos; el blog en inglés (www.navalny-en.livejournal.com), que es la versión internacional de su blog oficial (sin actualizar desde 2014), y el sitio oficial del Fondo para la lucha contra la corrupción (www.fbk.info). Si bien este sitio lleva su sello, no publica allí con su nombre. Es el sitio de la colectividad de su fundación en la cual trabajan actualmente unas treinta personas.

Por último, se encuentran los elementos diferenciadores del ecosistema de Navalny: las herramientas web. La primera es RosZKH (www.roszkh.ru), proyecto que tiene como objetivo apoyar al ciudadano en el cuidado de sus derechos, facilitándole una herramienta web con la que puede hacer una declaración directamente al Estado sobre problemas que pueda tener en relación con su lugar de vivienda.

Su funcionamiento es sencillo: el ciudadano selecciona el tipo de problema que quiere declarar, especifica la naturaleza del mismo con los datos de ubicación, e indica un correo al cual llega la verificación de la declaración y, una vez confirmada, esta se envía a la autoridad competente. Tanto el equipo de la fundación como el ciudadano pueden hacer monitoreo del estado de la declaración.

Imagen 4. Proyecto RosYama

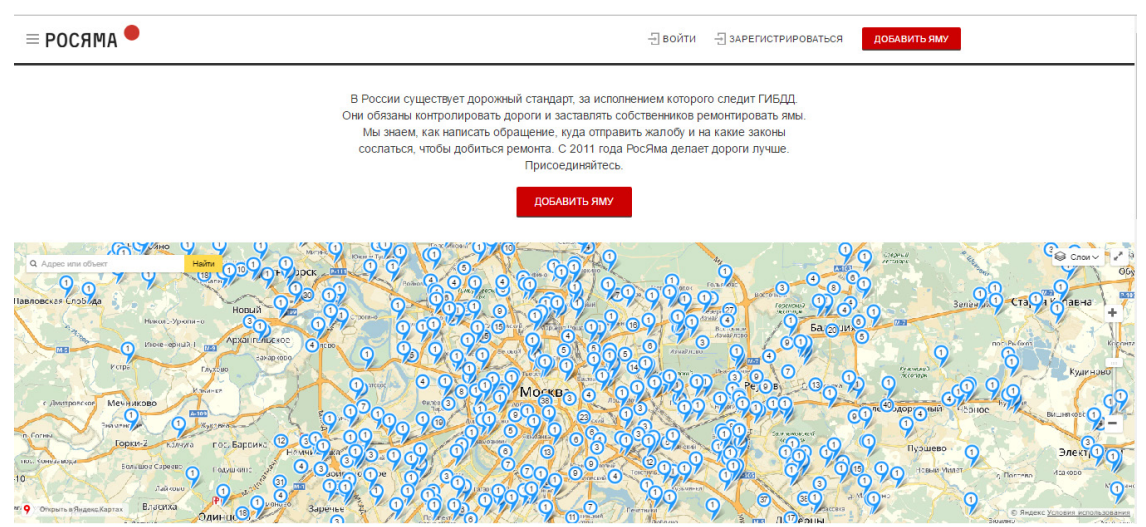

Fuente: www.rosyama.ru 
A diferencia de RosZKH, el proyecto RosYama (www.rosyama.ru) es menos privado: consiste en un mapa colaborativo (crowdsourced),${ }^{10} \mathrm{en}$ el que los ciudadanos denuncian grietas y aberturas en las vías rusas. Por ley, las dimensiones de las grietas en las carreteras no deben superar los $15 \mathrm{~cm}$ de longitud, $60 \mathrm{~cm}$ de ancho y $5 \mathrm{~cm}$ de profundidad; ${ }^{11} \mathrm{el}$ Estado ruso está en la obligación de vigilar las carreteras y repararlas en caso de daño. El proyecto se vale de fotografías y geolocalización para solicitarle a sus usuarios que localicen el problema, hagan una foto de él y lo ubiquen en el mapa.

\section{Formas de participación: el prosumidor y su pugna por la autoría}

Néstor García Canclini (1995) afirma que, incluso con la apropiación de los medios electrónicos de comunicación en lo público, los ministerios de cultura siguen "consagrados" a las bellas artes y, como máximo, se preocupan de la cultura popular tradicional. Ignorando por completo otras expresiones culturales, como los medios urbanos, donde se mueven el pensamiento y la sensibilidad masivos. De esta manera "se desentienden, por lo tanto, de los escenarios de consumo donde se forma lo que podríamos llamar las bases estéticas de la ciudadanía" (1995, p. 185).

Estos escenarios de consumo, que al día de hoy puede decirse son los que se generan con la penetración del internet en la cotidianidad y el aumento en el uso de las TIC-redes sociales, blogs, vlogs, etcétera-, supone también un cambio en las formas en que interactuamos, significamos y nos comportamos; ya que "la interacción cotidiana de las personas con estos artefactos digitales ha creado un vínculo mutuamente constitutivo de nuevos nichos culturales de producción de significado social" (Winocur, 2009, p. 13). Esos nichos culturales, sumados a la producción de significación, posibilitan una transición de la idea de audiencia homogénea y pasiva a la de un conjunto de individuos activos y atentos donde pasamos de ser un espectador a ser un actor que se apropia del texto, lo procesa y lo devuelve

10 Término utilizado para hacer referencia a la solicitud hecha a terceros para participar o aportar en la construcción colectiva de un proyecto.

11 Reseñado en el sitio web del proyecto RosYama, con base en la GOST R 50597-93. Carreteras y calles. Requisitos para la condición operacional, aceptables bajo los términos de seguridad vial, norma estatal de la Federación Rusa. Recuperado de https://bit.ly/2BNfXCJ 
con una producción de su propiedad. Esto es, "dejamos de ser audiencias y pasamos a ser productores, fans, movilizadores" (Rincón, 2012, p. 226).

El término de fan, aunque satanizado y caricaturizado en muchos casos, y que hace referencia a una persona devota o fiel a un texto específico, resulta un claro ejemplo de este tipo de apropiaciones y formas de asociarse actualmente. Para Jenkins (2010) los fans "constituyen una comunidad de consumidores especialmente activos, y que se hacen oír, cuyas actividades se centran en este proceso de apropiación cultural" (2010, p. 42). Los fans, aunque conscientes de la no pertenencia de las obras a las que son devotos, influyen tanto en ellas que logran llevarlas, de cierta manera, a ser textos de su propiedad. Son lectores que se apropian de los textos y los releen de una forma que sirve a diferentes intereses, y transforman la experiencia de la recepción en una cultura participativa rica y compleja (p. 37).

Es una especie de "piratería textual" en la que, durante el proceso, los fans sostienen una lucha con el autor por la posesión del texto y dejan de ser "un simple público [...] para convertirse en participantes activos en la construcción y circulación de significados textuales" (Jenkins, 2010, p. 38). Esta pugna entre fan y autor ha dejado una enseñanza respecto a las formas como se entiende la autoría y la producción de contenidos en los medios digitales en los que, una vez publicados, están sujetos a la lectura y modificación por parte de la audiencia. Como lo explica Jimena Zuluaga (2012, p. 252), "lo que hace que un contenido sea realmente digital" es el entendimiento de que su producción "no termina con la publicación" pues ello sería desconocer que en los espacios digitales se establecen la conversación y la interacción como norma: "después de publicar en línea el proceso de creación continúa porque el rol de las audiencias y de los autores, ahora difuso, genera un proceso continuo de construcción y reinterpretación de los mensajes y los contenidos" (2012, p. 252).

Dicho proceso de construcción y reinterpretación empodera a la audiencia en la medida en que las dinámicas de interacción audienciacontenido permiten que la primera se apropie del segundo y lo intervenga, al punto de transformarlo e incluso hacerlo propio. De la misma manera, la brecha entre el productor del contenido y quien lo consume es cada vez más pequeña y difusa; inclusive en el término mismo en el que ya no se separan los dos roles, sino que se unen: prosumidor. Si bien este término fue anticipado por otros autores desde mediados del siglo pasado, fue Alvin Toffler quien lo introdujo en su libro La tercera ola: 
Durante la primera ola, la mayoría de las personas consumían lo que ellas mismas producían. No eran ni productores ni consumidores en el sentido habitual. Eran, en su lugar, lo que podría denominarse "prosumidores" [...] Pues si examinamos atentamente la cuestión, descubrimos los comienzos de un cambio fundamental en la relación existente entre estos dos sectores o formas de producción. Vemos un progresivo difuminarse de la línea que separa al productor del consumidor. Vemos la creciente importancia del prosumidor (1981, pp. 171-172).

Por otro lado, José Octavio Islas (2008) afirma que en torno a la aplicación de prosumo en la Red y sobre cómo la web 2.0 ha transformado el comportamiento de los usuarios frente al contenido, estos transitan de "consumidores pasivos en activos prosumidores que han impulsado importantes transformaciones en el mercado al apostar por el recurso de la conversación, comprendiendo a Internet como efectivo multiplicador del capital intelectual" (2008, p. 36).

Profundizando en las características que separan a un prosumidor de una audiencia convencional, aparecen dos factores primordiales: la capacidad de búsqueda (in-forming) y la colaboración (Islas, 2008). La primera hace referencia a la capacidad de establecer y usar mecanismos propios de la búsqueda y el acceso a la información, lo que evidencia la autonomía del prosumidor frente al productor de contenido; partiendo, a su vez, de que toda persona con posibilidad de acceso a internet está en capacidad de cargar y descargar información. Respecto a la colaboración, se caracteriza al prosumidor por su afinidad con las ideas de solidaridad y construcción colectiva relacionadas con el diálogo y la interacción ya mencionadas.

A partir de todo lo anterior se pueden categorizar cuatro niveles de comportamiento para el análisis del prosumidor: consumo, producción, información y colaboración (tabla 1). El consumo hace referencia al medio y contenido con el que el individuo se está relacionando. La producción, por su parte, alude a los mecanismos de intervención sobre el contenido. La información se refiere a las estrategias y herramientas para la creación de nuevos contenidos o nueva información que alimenta la ya existente. Por último, la colaboración comprende las maneras como se amplía y fortalece el producto ya creado. Con relación a la tipología del individuo, se definen a su vez dos categorías: el ciudadano de a pie y el líder opositor (para este caso Alexei Navalny). La propuesta es analizar ambos tipos de individuo a partir de las cuatro características base del prosumo. 
Tabla 1. Comportamientos del prosumidor según su tipología

\begin{tabular}{|c|c|c|c|c|}
\hline Prosumidor & Consumo & Producción & Información & Colaboración \\
\hline $\begin{array}{c}\text { Tipología del } \\
\text { usuario. }\end{array}$ & $\begin{array}{c}\text { Medio y } \\
\text { contenido. }\end{array}$ & $\begin{array}{c}\text { Estrategias y } \\
\text { herramientas } \\
\text { intervención. }\end{array}$ & $\begin{array}{c}\text { Ampliación y } \\
\text { para obtener } \\
\text { nueva } \\
\text { información. }\end{array}$ & $\begin{array}{c}\text { fortalecimiento } \\
\text { del contenido } \\
\text { existente. }\end{array}$ \\
\hline
\end{tabular}

Fuente: elaboración propia basada en los referentes teóricos sobre el prosumo.

Como prosumidor, el ciudadano ruso se relaciona con diferentes tipos de medios: los medios de comunicación tradicionales, los medios digitales y las publicaciones de otros ciudadanos. Los contenidos que consume, para este caso, se relacionan con las diferentes posibilidades de ejercer su ciudadanía, es decir, accede a convocatorias sobre protestas o manifestaciones, encuentra aplicaciones que le permiten denunciar problemas en su ciudad y ve imágenes relativas a la situación actual de su país. De la misma manera interviene estos contenidos por medio de la participación activa en el diálogo con ellos: asiste a las manifestaciones de protesta y utiliza el distintivo característico (como la cinta blanca), ${ }^{12}$ captura y publica imágenes de lo que sucede a su alrededor. Es un ciudadano que se apropia de las tecnologías de la información y la comunicación para investigar y obtener información en la web y que está en capacidad de ampliar dicha información con el uso de sus dispositivos móviles y la utilización de herramientas colaborativas.

${ }^{12}$ Popularizada en su momento como símbolo del descontento hacia el resultado de las elecciones. El uso de las cintas blancas comenzó a darse primero en la web en contenidos de blogs, expandiéndose luego hasta las calles; aparecen además cintas blancas en los brazos de las personas y en objetos como los automóviles (Vassilieva, 2011). 
Imagen 5 . Protestantes con la cinta blanca, distintivo del movimiento, marzo de 2013

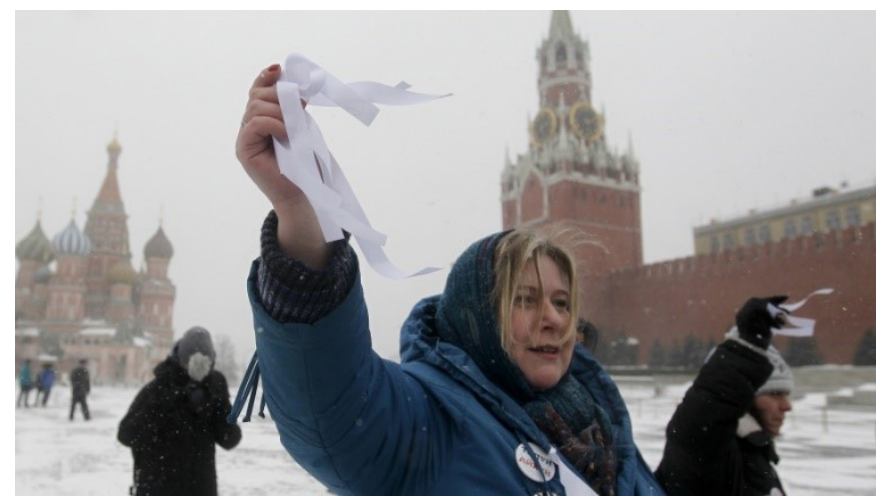

Fotografía de Maxim Shemetov, Reuters. Fuente: Global Politics (2013, diciembre 9, http://bit.ly/2osyPyr).

Del otro lado, está el rol de Alexei Navalny como figura visible de la oposición. Tanto su oficio como su trayectoria hacen de él un ciudadano empoderado, capaz de entender el contexto de los sucesos que ocurren en su país, analizarlos y producir un contenido que sea efectivo y visible para otros ciudadanos. Navalny participa activamente en la denuncia de la corrupción del gobierno al que se opone y hace veeduría de los procesos que de sus contenidos y aplicaciones se desprenden.

Como prosumidor, Navalny está siempre en constante diálogo con otros ciudadanos en la Red. Tiene una fuerte relación digital con los medios de comunicación y cuenta con perfiles activos en las redes sociales virtuales más populares, los cuales actualiza de forma permanente. Asimismo, es un blogger muy reconocido en su país, medio que utiliza para denunciar y convocar a otros ciudadanos para que se involucren en las acciones que él organiza. Adicionalmente tiene presencia frecuente en los medios de comunicación tradicionales. Una característica esencial de Alexei Navalny como productor de contenido es que sus estrategias llegan a los ciudadanos desde diferentes frentes comunicacionales, que pueden iniciar con una intervención en la calle y terminar con la interacción en los aplicativos webs. 
Tabla 2. Prosumidor en la Snow

Revolution según su tipología

\begin{tabular}{|c|c|c|c|c|}
\hline Prosumidor & Consumo & Producción & Colaboración & Información \\
\hline Ciudadano & $\begin{array}{c}\text { Se relaciona } \\
\text { en paralelo con } \\
\text { la información } \\
\text { publicada por } \\
\text { los líderes } \\
\text { opositores, } \\
\text { los medios de } \\
\text { comunicación y } \\
\text { otros ciudadanos } \\
\text { en redes. }\end{array}$ & $\begin{array}{c}\text { Interviene } \\
\text { participando en } \\
\text { las protestas, en } \\
\text { algunos casos } \\
\text { hablando con los } \\
\text { medios. Registra } \\
\text { y comparte en } \\
\text { tiempo real lo que } \\
\text { sucede. }\end{array}$ & $\begin{array}{c}\text { Se vale de la } \\
\text { consulta en la web } \\
\text { de la información } \\
\text { que le pueda ser } \\
\text { necesaria. Utiliza } \\
\text { sus dispositivos } \\
\text { móviles para } \\
\text { producir imagen, } \\
\text { sonido o video. }\end{array}$ & $\begin{array}{c}\text { Amplía el } \\
\text { contenido } \\
\text { existente al } \\
\text { participar, tanto } \\
\text { en acciones } \\
\text { físicas como en } \\
\text { la alimentación } \\
\text { de herramientas } \\
\text { web basadas en } \\
\text { crowdsourcing. }\end{array}$ \\
\hline $\begin{array}{c}\text { Líderes } \\
\text { opositores }\end{array}$ & $\begin{array}{c}\text { Se relacionan } \\
\text { en primera } \\
\text { instancia con } \\
\text { la información } \\
\text { oficial publicada } \\
\text { por el gobierno } \\
\text { y por otras } \\
\text { asociaciones. } \\
\text { Interactúan } \\
\text { en las } \\
\text { conversaciones } \\
\text { generadas por lo } \\
\text { que publican. }\end{array}$ & $\begin{array}{l}\text { Producen textos } \\
\text { de opinión en los } \\
\text { que denuncian } \\
\text { aspectos que no } \\
\text { concuerdan con } \\
\text { su punto de vista } \\
\text { y promueven } \\
\text { situaciones } \\
\text { que consideran } \\
\text { favorables. }\end{array}$ & $\begin{array}{l}\text { Se valen de la } \\
\text { consulta web, } \\
\text { los medios de } \\
\text { comunicación, } \\
\text { las leyes, y de las } \\
\text { informaciones } \\
\text { publicadas por } \\
\text { otros líderes o } \\
\text { ciudadanos. }\end{array}$ & $\begin{array}{c}\text { Amplían el } \\
\text { contenido } \\
\text { existente con } \\
\text { la creación de } \\
\text { herramientas } \\
\text { colaborativas en } \\
\text { las que, de la mano } \\
\text { con el ciudadano, } \\
\text { se construyen } \\
\text { contenidos de } \\
\text { carácter social. }\end{array}$ \\
\hline
\end{tabular}

Fuente: Elaboración propia.

En este punto es importante mencionar que si bien es evidente que los modos de participación (como las formas de prosumo) han detonado nuevas formas de ser y estar en sociedad que potencian el flujo y producción de la información, estas son consecuencia a su vez de otros conceptos como los de audiencia y ciudadanía, los cuales han tenido también revisiones en sus significados tradicionales gracias a la llegada de las NTIC. ${ }^{13}$ Esto supone entender que, así como el prosumo detona la transmedialización de un contenido, este es en sí producto de las formas de ser y estar en la web: las formas de ser audiencia y las formas de ciudadanía.

13 Sigla para "Nuevas tecnologías de la información y la comunicación". 


\section{Ser una celebridad ciudadana, la posibilidad de ser visto}

Para Rosalía Winocur "[1]a visibilidad garantiza la inclusión en un mundo cuya representación se ha desplazado de lo palpable a lo comunicable" $(2009$, p. 69), lo que le permite al individuo pensarse como sujeto existente en relación con el otro y consigo mismo.

En relación con el otro por la inclusión y la pertenencia, posibles gracias a las redes sociales y las comunidades virtuales, donde el usuario puede interactuar, dialogar, compartir y, sobre todo, sentirse parte de una comunidad o red. Considerando que "lo que se ha modificado no es el deseo de pertenecer, sino el sentido y las formas de pertenencia" (Winocur, 2009, p. 77).

Respecto al nivel de existencia más íntimo (consigo mismo), Omar Rincón afirma que el teléfono celular aparece como un artefacto más apto para la intimidad, donde el individuo registra y conserva su vida personal. Es desde los celulares donde hoy se tejen los relatos de las subjetividades "y los nuevos modos de ser comunidad y esfera pública [...] En el celular somos orales, luego somos ciudadanos, luego podemos gritar, luego contamos, queremos contar" (2012, p. 231). Pero el asunto comienza a generar una especie de crisis identitaria; históricamente las personas que ocupan el lugar de la recepción en el proceso comunicativo han recibido distintos nombres según el medio, la disciplina o la rama con la cual se les mire: se pueden listar, entre otros términos, los de receptor, audiencia, público, masa, usuario, etcétera. Es ahí donde surge la pregunta ¿̇uál de todas estas posibilidades es la que ocupamos actualmente?

Para Rincón (2012, p. 232), "la revolución tecnológica, comunicativa y política de nuestro tiempo" nos ha permitido ejercer cualquier rol en el proceso de comunicación, desde productores, periodistas, fans y seguidores, "todo, menos audiencias". Esto gracias a que no somos una masa simplemente, sino un conjunto de actores activos que son, en simultáneo: "1.0 (silencio), 2.0 (masa), 3.0 (comunidad) y 4.0 (celebrities ciudadanas)" (Rincón, 2012, p. 182).

El silencio hace referencia al momento en que el ciudadano no accedía a la información, donde solo unos pocos ilustrados y poderosos tenían acceso a la verdad mientras que al ciudadano corriente se le exigía no participar porque no contaba. La masa aparece con la llegada de la modernidad, el periodismo, el cine, la radio y la televisión. En ese momento se comenzó 
a ser rating, estadísticas. La comunidad, como consecuencia de las nuevas tecnologías, entiende al ciudadano como productor. Por último, se es al tiempo activista, fan, movilizador, productor, etcétera. El individuo rompe la pantalla y quiere ser una celebridad, quiere visibilidad, quiere estar en las esferas públicas para buscar reconocimiento. "¿Ciudadanías débiles? Tal vez, pero útiles para ganar autoestima pública y para ganar poder en la vida cotidiana. Ciudadanías lights que se hacen posibles en comunidades en red. iQueremos la pantalla, no nos conformamos con medios!" (Rincón, 2012, p. 233).

La tabla 3 propone como matriz de análisis los cuatro momentos de los que habla Rincón, entendiendo que según la circunstancia se puede estar en una de las cuatro categorías o en todas a la vez.

Tabla 3. Las formas de ser audiencia

\begin{tabular}{|c|c|c|c|c|}
\hline Individuo & 1.0 Silencio & 2.0 Masa & $\begin{array}{c}3.0 \\
\text { Comunidad }\end{array}$ & $\begin{array}{c}4.0 \text { Celebrity } \\
\text { ciudadana }\end{array}$ \\
\hline $\begin{array}{c}\text { Tipología del } \\
\text { usuario. }\end{array}$ & $\begin{array}{c}\text { Las acciones } \\
\text { en las que } \\
\text { calla, no cuen- } \\
\text { ta o es igno- } \\
\text { rado. }\end{array}$ & $\begin{array}{c}\text { Las acciones } \\
\text { que lo } \\
\text { convierten } \\
\text { en una } \\
\text { estadística, } \\
\text { en un conglo- } \\
\text { merado } \\
\text { homogéneo. }\end{array}$ & $\begin{array}{c}\text { Las acciones } \\
\text { en las que co- } \\
\text { labora comu- } \\
\text { nitariamente. }\end{array}$ & $\begin{array}{c}\text { Las acciones } \\
\text { en función de } \\
\text { su visibilidad. }\end{array}$ \\
\hline
\end{tabular}

Fuente: Elaboración propia a partir de Rincón (2012).

A propósito de la aplicación de las formas de ser audiencia (Tabla 3) al caso de estudio en la tabla 4, de Alexei Navalny se puede decir que es una gran celebridad ciudadana y como tal, es muy poco el silencio. Las celebridades ciudadanas se caracterizan por su gran nivel de visibilidad en las esferas públicas de la virtualidad y Navalny sabe estar en ellas. Su nivel de influencia es muy alto, contando con promedios de seguidores en las redes sociales digitales de miles de usuarios, y en algunos casos, como en Twitter, con casi dos millones. ${ }^{14}$ Aun con su éxito digital, sus

${ }^{14}$ Aproximadamente: 75692 en Instagram, 338933 en Facebook y 1775833 en Twitter. (Datos tomados de sus perfiles en las redes sociales ya mencionadas. Consultado el $3 \mathrm{de}$ febrero de 2017). 
acciones lo llevaron a estar en la categoría de silencio en el momento en que fue condenado por malversación de fondos en 2013. ${ }^{15}$

Tabla 4. Aplicación de las formas de ser audiencia al caso Navalny

\begin{tabular}{|c|c|c|c|c|}
\hline Individuo & 1.0. Silencio & 2.0 Masa & 3.0 Comunidad & $\begin{array}{l}\text { 4.0 Celebrity } \\
\text { ciudadana }\end{array}$ \\
\hline Ciudadano & $\begin{array}{c}\text { En las acciones } \\
\text { lideradas por el } \\
\text { gobierno. Cuando } \\
\text { sus denuncias no } \\
\text { surten efecto. }\end{array}$ & $\begin{array}{l}\text { Cuando participa } \\
\text { de acciones co- } \\
\text { lectivas como las } \\
\text { manifestaciones } \\
\text { de protesta o un } \\
\text { encuentro cele- } \\
\text { bratorio }\end{array}$ & $\begin{array}{l}\text { Cuando participa } \\
\text { en función de } \\
\text { lograr objetivos } \\
\text { comunes, como } \\
\text { en el caso de Ros- } \\
\text { Yama. } \\
\text { También cuando } \\
\text { interactúa con } \\
\text { contenidos de } \\
\text { bloggers. }\end{array}$ & $\begin{array}{c}\text { La visibilidad del } \\
\text { ciudadano se esta- } \\
\text { blece en la medida } \\
\text { que existe, partici- } \\
\text { pa y comparte en } \\
\text { redes sociales }\end{array}$ \\
\hline $\begin{array}{c}\text { Líderes } \\
\text { opositores }\end{array}$ & $\begin{array}{l}\text { El líder opositor } \\
\text { participa, tiene } \\
\text { muy poco silencio } \\
\text { al ser el rostro y } \\
\text { la voz de muchos. } \\
\text { Pero es silencio } \\
\text { una vez se con- } \\
\text { vierte en preso } \\
\text { político. }\end{array}$ & $\begin{array}{l}\text { Es masa cuando } \\
\text { se une a mani- } \\
\text { festaciones y en- } \\
\text { cuentros como un } \\
\text { ciudadano más. } \\
\text { Es masa al enten- } \\
\text { derse como parte } \\
\text { del colectivo al } \\
\text { que representa. }\end{array}$ & $\begin{array}{l}\text { Es comunidad } \\
\text { cuando propone } \\
\text { espacios de traba- } \\
\text { jo colaborativo. }\end{array}$ & $\begin{array}{l}\text { Su naturaleza es } \\
\text { en sí visible, tiene } \\
\text { alta presencia en la } \\
\text { web, da discursos, } \\
\text { aparece en medios } \\
\text { de comunicación, } \\
\text { le hacen reseñas y } \\
\text { es el protagonista } \\
\text { del movimiento al } \\
\text { cual pertenece. }\end{array}$ \\
\hline
\end{tabular}

Fuente: Elaboración propia.

Del otro lado se encuentra el ciudadano y sus formas de ser audiencia. El ciudadano es silencio desde la perspectiva del gobierno, es decir, para los medios oficiales que evitan incluir en sus transmisiones mensajes y

15 En febrero de 2017 se da un nuevo caso de condena contra el opositor ruso, esta vez impuesta por el Tribunal Leninski de la ciudad de Kírov, argumentando malversación de fondos y que supone una suspensión de cinco años para Navalny. Dicho proceso ya tenía un antecedente con la condena a cinco años de cárcel, impuesta en julio de 2013. Este último suceso ha generado diversas reacciones respecto a si se asiste a una persecución política, teniendo en cuenta que en el 2018 son las elecciones presidenciales en Rusia y Navalny había anunciado su intención de candidatura (Yegórov, 2017). Adicionalmente, el 26 de marzo de 2017, Navalny vuelve a ser noticia al ser tomado preso durante las protestas contra la corrupción ocurridas el mismo día y convocadas por él (BBC Mundo, 2017). 
contenidos que reivindiquen sus intereses; el día de la manifestación en la plaza de Bolotnaya en Moscú, los medios oficiales rusos solo transmitieron las manifestaciones que se dieron en apoyo a Vladimir Putin.

El ciudadano se convierte en masa una vez sale a la calle a manifestarse y atiende a las acciones colectivas a las que es convocado. Es en este momento en el que se convierte en una cifra: 50000 personas se manifestaron el 10 de diciembre en la Plaza Bolotnaya y 100 manifestantes fueron arrestados por la policía (Global Nonviolent Action Database, s. f). El ciudadano es comunidad cuando actúa individualmente en función de un bien común. Las estadísticas que se ofrecen en el sitio oficial del proyecto RosYama muestran que, a mayo de 2017, la red para el reporte de grietas en las vías creada por la comunidad ha conseguido hacer reparar 24213 aberturas en las calles y carreteras.

Dado el carácter de la serie de protestas de la Snow revolution, el ciudadano participante de la misma cumple con todas las características para ser un ciudadano de la Red (netizen), estando siempre atento y vigilante a lo que sucede para actuar. El ciudadano ruso que aceptó la invitación por redes para salir a las calles a protestar es el mismo que, aún hoy, saca su teléfono celular para tomarle una foto y reportar una grieta en las vías. Este ciudadano es el que se siente motivado para cooperar colectivamente de diferente manera: le interesa alcanzar los objetivos comunitarios en los que se denuncia la corrupción en su país y lo mueve un sentimiento de patriotismo y pertenencia hacia este. 
Ciudadanías: vigilancia y ciudadanía digital

García Canclini (1995) habla sobre una sociedad civil mundial que se caracteriza por un proceso de integración transnacional, por tener una capacidad decisoria mucho mayor que la de los partidos políticos, sindicatos y movimientos sociales de alcance nacional. "Concebir el ejercicio de la ciudadanía sólo a nivel local o nacional es el equivalente político de enfrentar a Sony o Nestlé con estrategias de comercio minorista” (p. 192).

Esta relación transnacional en la que convergen diversos repertorios, se relaciona con las formas como los nuevos medios de comunicación afectan a la ciudadanía. Para Jenkins (2008) los nuevos medios operan con principios diferentes a los que eran usados anteriormente por los medios de la comunicación de masas. Los nuevos se caracterizan por la posibilidad de acceder tanto a ellos como a la información, por la posibilidad del ciudadano de hacerse partícipe y porque posibilitan una comunicación recíproca donde sus partes son iguales y no hay un mensaje que va de uno a muchos.

Esta posibilidad de acceso a la información conlleva la idea de que ahora se es un ciudadano informado, que tiene a su disposición la información necesaria para ejercer su ciudadanía. Sin embargo, esta concepción de ciudadano no implica necesariamente una condición más autónoma del mismo pues, si bien puede acceder a la información, es probable que no sepa qué hacer con ella. Para Jenkins (2008) a lo que se hace referencia en términos de ciudadanía actualmente es a una especie de vigilancia, a una forma de colaboración comunitaria: el "tránsito de la concepción individualizada del ciudadano informado hacia el concepto cooperativo del ciudadano vigilante" (p. 227).

El ciudadano vigilante, más que dispuesto a llevar la iniciativa, tiende a estar atento y observante, listo para actuar cuando sea necesario: y sabe cómo hacerlo, no es ausente sino alerta. Se ve al ciudadano vigilante más como un actor que establece relaciones colaborativas con otros, como alguien "entendido en ciertos ámbitos, algo al tanto de otros, operando en un contexto de confianza mutua y recursos compartidos" (Jenkins, 2008, p. 227).

Por otro lado, como lo señala Zuluaga, los ciudadanos del siglo Xx tienen la capacidad de comunicarse a través de la Red; son nuevas formas de ciudadanías capacitadas en el uso de los medios de comunicación. Siempre 
están online y visibles. Productores de un lado, consumidores del otro, son netizens: "Las audiencias activas. Lo que en inglés se llama netizens -algo así como ciudadanos de la red" (Zuluaga, 2012, p. 242).

Los ciudadanos de la Red están empoderados, combinan las características del prosumidor, de la sociedad civil transnacional y del ciudadano vigilante. En este punto RosYama entra como un claro ejemplo de las formas de vigilancia ciudadana, se trata de ciudadanos de a pie dispuestos a participar, a involucrarse con las causas, a denunciar. Quienes publican en proyectos como RosYama son personas que cumplen con las características antes mencionadas del prosumo: colaboran, producen contenidos y rastrean información con el fin de ser y estar en comunidad.

La fundación Fondo para la lucha contra la corrupción supo aprovechar esto dotando a sus proyectos de mecanismos para facilitar la denuncia ante las entidades del Estado. Así, aplicaciones como RosYama cuentan con versiones tanto en iOS como en Android que posibilitan la publicación desde el teléfono, lo que hace al sitio más eficiente (Hinojosa, 2012).

Imagen 6. Mapa colaborativo de RosYama

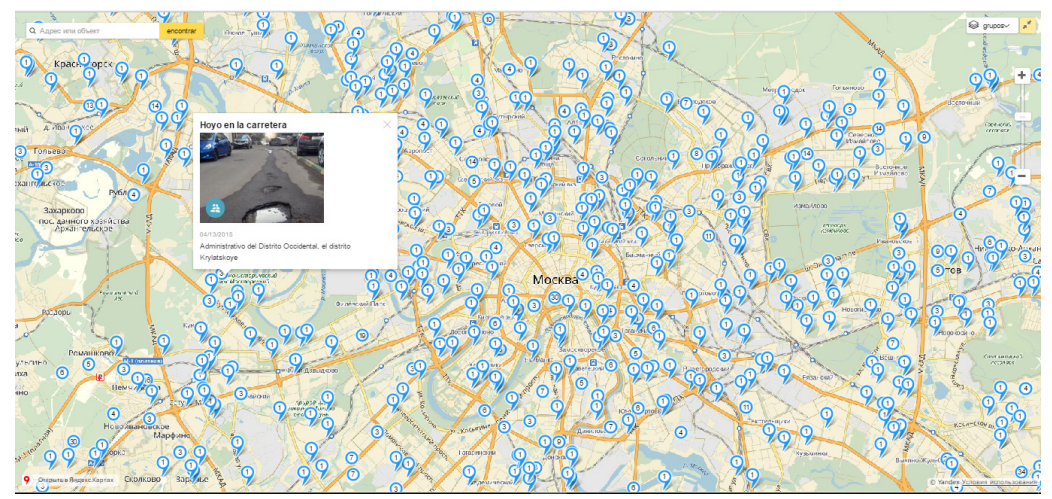

Fuente: Mapa colaborativo de Moscú construido a partir de los reportes de ciudadanos rusos en el proyecto RosYama (https://rosyama.ru/).

De la misma manera, se realizan conexiones para facilitar el registro desde los perfiles de las principales redes sociales: Facebook, VKontakte y Google +, con lo cual se le ahorra al ciudadano el tener que llenar los tradicionales formularios de registro. Como resultado, se encuentra un servicio que facilita la denuncia de los deterioros en las vías del país. Con un resultado de 88595 denuncias y 24213 fallos corregidos. 


\section{Conclusiones}

A propósito de las formas de agencia y relacionamiento, las redes sociales y en general los medios digitales posibilitan el activismo político al establecer nuevos principios operacionales diferentes a los ya establecidos en los medios tradicionales como la televisión y la radio. Conceptos como los de accesibilidad, interactividad, participación y reciprocidad permiten que se establezca una comunicación entre iguales y no de uno a muchos.

Estas facilidades para comunicarse políticamente en la web se basan en que las fronteras entre lo íntimo y lo público se difuminan, lo cual hace que el usuario transite constantemente entre lo personal, lo familiar y lo social mientras se encuentra online. En este sentido, se recomienda tener en cuenta tres factores al momento de pensar en contenidos transmediales cuyo fin sea detonar la cooperación y la participación ciudadana, a saber: los ámbitos de pertenencia, los modos de interacción y los ecosistemas mediáticos.

Los ámbitos de pertenencia se refieren a las formas de ser y estar en sociedad, a la importancia de permitir que quien interactúe con la convocatoria pueda sentirse en red, en comunidad, en visibilidad. Una cosa es poner como foto de perfil una cinta blanca y otra es amarrarla a la puerta del carro, pero ambas constituyen una misma acción: la respuesta a una invitación para identificarse como comunidad.

De igual manera, la posibilidad de estar conectado le permite hacer una transición entre ciudadano-audiencia a ciudadano-prosumidor o netizen; esta transición es posible gracias a que para entrar en los medios digitales solo se necesita contar con un dispositivo móvil y una conexión a internet, es decir, las puertas abiertas al prosumo. Lo cual se hace evidente con la implementación de aplicaciones como RosYama y RosZKH, en las que el usuario, además de pertenecer a una comunidad, se encuentra con un sitio donde la información ya está filtrada según su necesidad y donde se apela a su capacidad de consumir y producir contenido comunicacional.

Esta forma de pensar al individuo implica considerar también sus modos de interacción: cómo y en qué momento el ciudadano está 
inclinado a participar activamente y de qué manera se puede detonar dicha participación. Lo anterior implica una revisión de las formas como se ha entendido históricamente al usuario y entender que este puede ser múltiples audiencias al tiempo y que se encuentra en un tránsito constante entre la generalidad de la masa y la individualidad de la celebridad, acomodándose a estas según el momento del día, el medio con el que interactúa y el interés que en él se suscita.

Por último, la necesidad de compaginar las formas de comunicación de la llamada cultura de la convergencia y los ecosistemas mediáticos que se entretejen: las redes de contenidos y plataformas que configuran la estrategia de comunicación transmedia. El entramado de contenidos producidos por, y en torno a Alexei Navalny, son un claro ejemplo de cómo se puede construir una estrategia de comunicación transmedia que posibilite la movilización social por medio de contenidos que se dirijan a ejercer la ciudadanía tanto de manera vigilante (estando atento a lo que sucede en el entorno) como en la web (actuando de manera colaborativa y fortaleciendo las aplicaciones basadas en el crowdsourcing); contenidos que promuevan acciones ciudadanas como la veeduría, el monitoreo a los procesos y la acción colectiva. Estrategias de comunicación que extiendan el relato no desde la narración sino desde las formas de ser y estar.

Para finalizar, si bien existe ya un acuerdo respecto a que el nivel narrativo de un contenido no es inherente a su carácter transmedial (la llamada expansión), pareciera que las metodologías, las categorías de análisis y las estrategias de diseño se quedaran cortas cuando se trata con otros tipos de comunicación.

Lo anterior arroja una serie de inquietudes para abordar: cacaso el concepto de narrativa transmedia se queda corto para describir procesos que no son necesariamente narrativos? ¿Se podría hablar mejor de estrategia transmedia? ¿Cuáles son las metodologías de trabajo para potenciar las capacidades de las audiencias en su ejercicio de ciudadanía? Interrogantes que exigen una reflexión que excede las posibilidades de este trabajo. Lo que sí se puede afirmar a partir de este análisis es que participar de una estrategia que combine diferentes formas de convocatoria, medios de comunicación y mecanismos de participación, supone un ejercicio de ciudadanía múltiple y amplificada. 


\section{Referencias}

Brics. (2013). Contexto histórico-político. Complutense Wordpress. Recuperado de http://bit.ly/2pWqy76

Cliff, C. (2017). Transmedia Storytelling Strategy. How and why producers use transmedia storytelling for competitive advantage (tesis de Maestría). Queensland University of Technology, Brisbane, Australia. Recuperado de https://bit.ly/2CFHdEI

Ermoshina, K. (2014). Democracy as pothole repair: Civic applications and cyberempowerment in Russia. Cyberpsychology: Journal of Psychosocial Research on Cyberspace, 8(3), 24-37. doi: https://doi.org/10.5817/CP20143-4

Espada, B. (2016). Perestroika. La revolución de las esperanzas. SobreHistoria.com. Recuperado de http://bit.ly/2pYLUjm

Gabowitsch, M. (2012). A Strategy for Russia's Snow Revolution. Social Europe. Recuperado de http://bit.ly/2cdXK4S

García Canclini, N. (1995). Consumidores y ciudadanos. Conflictos multiculturales de la globalización. México: Grijalbo.

Genette, G. (1989). Palimpsestos. La literatura en segundo grado. Madrid, España: Taurus.

Genette, G. (2001). Introducción. En Umbrales (pp. 9-17). México: Siglo XXI.

Gessen, M. (2014). Russian repercussions of anti-Putin Snow Revolution. Irish Examiner. Recuperado de http://bit.ly/2cyJdE2

Global Nonviolent Action Database (s. f). Russians protest against election fraud (Snow Revolution), 2011-2012. Recuperado de http:// bit.ly/2cyKYB6

Hayes, G. (2011). The Transmedia Hierarchy of Needs [comentario de blog]. Personalizemedia.com. Recuperado de https://bit.ly/2EWHaGW 
Hinojosa, C. (2012, noviembre 20). RosYama, una interesante iniciativa ciudadana para mejorar las carreteras rusas [comentario de blog]. Tecnocarreteras. Recuperado de http://bit.ly/2pNWRZV

Islas, J. O. (2008). El prosumidor. El actor comunicativo de la sociedad de la ubicuidad. Palabra Clave, 11(1), 29-39. Recuperado de https://bit.ly/2QYJJQQ Jenkins, H. (2003, enero 15). Transmedia Storytelling. MIT Technology Review [en línea]. Recuperado de http://bit.ly/22v1yRK

Jenkins, H. (2008). Convergence Culture. La cultura de la convergencia de los medios de comunicación. Barcelona, España: Paidós.

Jenkins, H. (2010). Piratas de textos: fans, cultura participativa y televisión. Madrid, España: Paidós.

Kinder, M. (1991). Playing with Power in Movies, Television, and Video Games: From Muppet Babies to Teenage Mutant Ninja Turtles. Berkeley, CA: University of California Press.

Klastrup, L., \& Tosca, S. (2004). Transmedial Worlds - Rethinking Cyberworld Design. En 2004 International Conference on Cyberworlds, Noviembre 18-20, 2004. Los Alamitos, CA. doi: 10.1109/CW.2004.67 Loffe, J. (2011). Snow Revolution. The New Yorker. Recuperado de http:// bit.ly/2caTzIt

Montoya, D. F., Vásquez Arias, M., y Salinas Arboleda, H. (2013). Sistemas intertextuales transmedia: exploraciones conceptuales y aproximaciones investigativas. Revista Co-herencia, 10(18), 137-159. Recuperado de https://bit.ly/2M9bDkx

O'Flynn, K. (2012, febrero 15). Toys cannot hold protest because they are not citizens of Russia, officials rule. The Guardian. Recuperado de http://bit.ly/2n8LMgM

Osborn, A. (2011). Bloggers who are changing the face of Russia as the Snow Revolution takes hold. The Telegraph. Recuperado de http://bit. ly/2c2sVRM

Pilgun, M., y Gradoselskaya, G. V. (2015). Political Communication on Facebook: Russian Case. Revista Latina de Comunicación Social, (70), 726749. doi: https://doi.org/10.4185/RLCS-2015-1068en

Protestas en Rusia: arrestan a al menos 500 manifestantes y condenan al líder opositor Alexei Navalny a 15 días de prisión. (2017). BBC Mundo. Recuperado de http://bbc.in/2nDjq1h 
Rincón, O. (2012). La vida más allá de las audiencias. Rompiendo las pantallas, buscando la celebridad. En J. Bonilla, M. Cataño, O. Rincón, y J. Zuluaga, De las audiencias contemplativas a los productores conectados. Mapa de los estudios y de las tendencias de los ciudadanos mediáticos (pp. 179-237). Cali, Colombia: Sello Editorial Javeriano.

Scolari, C. A. (2013). Narrativas Transmedia. Cuando todos los medios cuentan. Barcelona, España: Deusto.

Shuster, S. (2012). Can This Man Save Russia? Time (pp. 34-37). Toffler, A. (1981). La tercera ola. Bogotá, Colombia: Ediciones Nacionales Círculo de Lectores. Disponible en http://bit.ly/1V91C8x

Vanden Heuvel, K. (2015). The Russian Evolution. The Nation, pp. 3-6. Vassilieva, M. (2011, diciembre 9). Russia protest: White ribbon emerges as rallying symbol. BBC News. Recuperado de http://bbc.in/ZaSR3Z Volkov, D. (2012). Origins, Dynamics and Consequences of the Russian Protest Movement. Institute of Modern Russia. Recuperado de https://bit. ly/2RIXbfv

Volkov, D. (2013). Protest Movement in Russia through the Eyes of its Leaders and Activists [artículo de investigación en línea]. Recuperado de https://bit.ly/2VhAuIt

Weir, F. (2011). In Russia, a blogger takes on powerful Putin. Christian Science Monitor. Recuperado de http://bit.ly/2c3za9E

Winocur, R. (2009). Robinson Crusoe ya tiene celular: La conexión como espacio de control de la incertidumbre. México: Siglo XXI.

Yegórov, O. (2017, febrero 9). La condena del opositor Navalni, ¿un proceso político? Russia Beyond. Recuperado de http://bit.ly/2mOnHMh Zuluaga, J. (2012). Internet: nuevas audiencias, ¿nuevos ciudadanos? En J. Bonilla, M. Cataño, O. Rincón, y J. Zuluaga, De las audiencias contemplativas a los productores conectados. Mapa de los estudios y de las tendencias de los ciudadanos mediáticos (pp. 239-262). Cali, Colombia: Sello Editorial Javeriano. 